\title{
Application of Laser Induced Breakdown Spectroscopy in Soil Element Analysis of Watershed
}

\author{
C. P. CHEN, L. HEI*, S. C. YU, W. L. CHEN, M. X. CAI
}

Key Laboratory of the Pearl River Estuarine Dynamics and Associated Process Regulation, Ministry of Water Resources, Pearl River Hydraulic Research Institute, Pearl River Water Resource Commission, Guangzhou 510611, China

\begin{abstract}
With the rapid development of spectroscopy technology, laser induced breakdown spectroscopy (LIBS) has become the focus of elemental analysis technology in recent years. With its advantages of non-destructive testing, rapid and multi-element detection, LIBS has been successfully applied to the analysis of geochemical characteristics of soil elements in river basins. The application of LIBS technology in soil elemental analysis of watershed is reviewed in detail. The accuracy of LIBS technology in soil element analysis is studied with the Masha River Basin as the research area. On this basis, the key problems in the process of soil element analysis, such as spectral enhancement methods and quantitative analysis methods, were analyzed. The analysis results show that the accuracy of elemental analysis between LIBS and traditional chemical methods is not much different, but the analysis time of LIBS method is shorter. Methods such as MLR, PLSR, and internal standard methods can improve the fit of the calibration curve and reduce the quantitative analysis error. By changing parameters such as laser energy and delay time, the spectral intensity can be enhanced to reduce the effects of matrix effects. In the process of elemental analysis, the effects of soil physical and chemical parameters should be considered comprehensively, and appropriate quantitative analysis methods should be adopted to improve the accuracy of the analysis results.
\end{abstract}

\section{Introduction}

Soil is an important part of the natural environment and an important resource for human survival. However, with the continuous growth of the world population, the rapid development of industry and the acceleration of urbanization, major river basins are faced with problems such as soil erosion, soil desertification, salinization and heavy metal pollution [1,2]. Among them, soil erosion leads to a decline in land productivity, and it also causes siltation of rivers, lakes and reservoirs. Heavy metal pollution in the soil can seriously affect the growth of crops. Heavy metals in the soil reach the human body through the food chain, and the accumulation of heavy metals can seriously endanger human health $[3,4]$. In such a new environment, environmental and soil researchers focus on the prevention and control of watershed soil problems, and soil element detection and analysis has become an indispensable part of solving watershed soil problems [5].

At the present stage, the detection of soil elements relies mainly on on-site sampling and laboratory testing. Traditional methods for detecting soil elements are: Inductively Coupled Plasma Optical Emission Spectrometer/Mass Spectrometry (ICP-OES or ICP-MS), High Performance Liquid Chromatography, Atomic Absorption Spectroscopy (such as FLAA, GFAA, HGAA, and CVAA), and Spectrophotometer Colorimetric [6-8].
Although the current soil element analysis method is more accurate, it is necessary to carry out field sampling in large-area soil quality assessment and soil ecological restoration test, and the sample pretreatment process is complicated and the analysis time is long. the main advantages of the LIBS Technology, unlike other traditional methods of analysis, are as follows:

(1) LIBS enable real-time detection without pretreatment of the sample before analysis, and is not constrained by sample morphology (solid, liquid or gas).

(2) LIBS can achieve simultaneous analysis of multiple elements.

(3) The analysis time is short and it is not easy to cause secondary pollution of the sample.

Therefore, it is widely used in watershed soil environment testing. Since the $20^{\text {th }}$ century, many experts and scholars at home and abroad have successfully applied the LIBS technology to detect many heavy metal elements such as aluminum, copper, iron, zinc, lead, chromium, cadmium phosphorus and potassium in various watersheds. In further studies, Aglio et al. [9] applied the LIBS technique to rapid analysis of soil heavy metals such as $\mathrm{Cr}$ and $\mathrm{Pb}$. Capitelli $\mathrm{F}$ et al. [10] compared average with relative standard deviations from LIBS and ICP-AES in soil heavy metal detection, and the error did not exceed $6 \%$. Xue et al. [11] used LIBS technology to analyze the spatial distribution characteristics of phosphorus and potassium in small watersheds. The results show that the two elements are

\footnotetext{
* Corresponding author. Tel: +862085116685, E-mail: hidige@sina.com.cn
} 
enriched in areas with better water conditions and better vegetation growth.

Considering that LIBS technology has a good application prospect in watershed soil environment monitoring, the application of LIBS technology in soil elemental analysis of watershed is reviewed in detail. The accuracy of LIBS technology in soil element analysis is studied with the Masha River Basin as the research area. At the same time, the technical difficulties and future development trends of the technology in soil

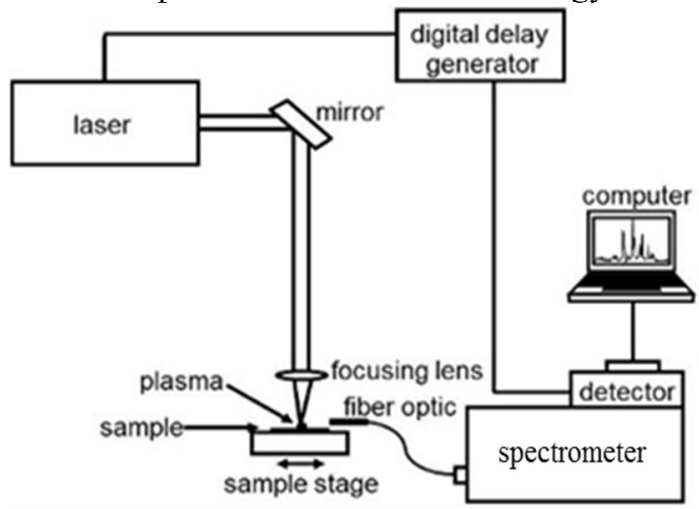

Fig.1 Schematic diagram of the LIBS experiment set-up element analysis are discussed.

\section{Principles of LIBS}

The LIBS technology principle is shown in Figure 1. The high-frequency pulsed laser light emitted by the $\mathrm{Nd}$ : YAG laser is focused on the surface of the material through the lens. Under the action of the pulsed

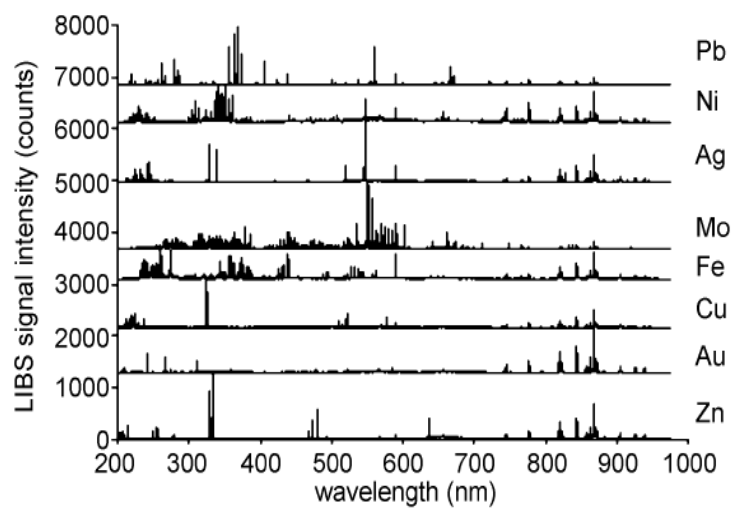

Fig.2 Schematic diagram of plasma spectrum laser, the material on the surface of the sample of the laser ablation zone instantaneously melts, vaporizes, and finally ionizes to form a high-temperature plasma. The generated plasma can vaporize most of the elements in the sample and excite them to high energy states [12]. When the sample cools, a large number of atoms and ions in the excited state will gradually transition to the low energy state or the ground state. In this process, specific wavelength lines of the corresponding elements will be generated [13-15]. Specifically shown in Figure 2. The optical system is used to collect the spectral signals. The corresponding characteristic peak intensity in the spectrum can be used to determine the elemental composition of the substance and the spectral intensity can be used to quantitatively analyze the content of the element.

\section{LIBS for soil elemental analysis in the Masha River Basin}

\subsection{Sample Preparation}

The soil samples were collected from various areas along the South Russian River in the tributary of the Masha River in Qinglong County, Guizhou Province. The collected soil samples were mixed and air-dried to remove foreign matter such as stones, weeds and animal and plant residues in the samples. In the middle grinding, the ground sample was passed through a 100-mesh sieve, and then a small amount of sieved soil sample was pressed into a cake having a thickness of about $3 \mathrm{~mm}$ and a diameter of $13 \mathrm{~mm}$ by a bench presser under a pressure of $20 \mathrm{t}$.

\subsection{Standard sample selection}

The selected standard soils were GBW07404, GBW07405, GBW07407, GBW07408, and were re-sampled with quartz sand with a purity of $99.84 \%$. A total of 8 samples with different concentration gradients were obtained, and 8 groups of samples were sequentially subjected to tableting.

\subsection{Standard curve drawing and element analysis}

After the basic working parameters are set, the spectrum of the soil sample is measured by laser spotting, as shown in Figure 3. The standard curve is drawn by using the spectral information of different concentration elements, and the unknown sample is compared with the curve to obtain the content of the element in the unknown sample. The relationship between the content of each specific element and the integrated intensity is obtained through experiments, and the corresponding standard curve is drawn. The following figure shows the standard curve $\mathrm{Cr}$. 


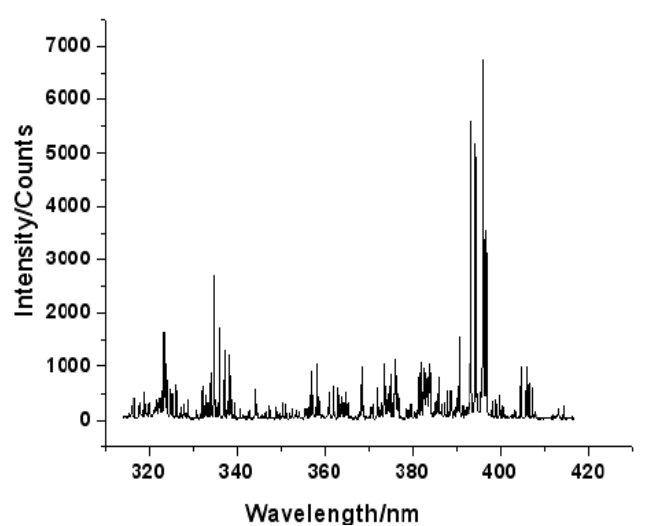

Fig.3 Spectral intensity map of soil elements

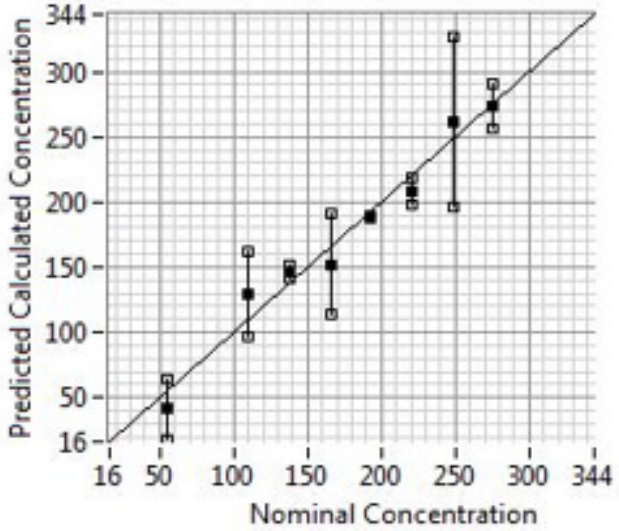

Fig.4 Standard curve of the Cr element

The spectral analysis of all the soil samples to be tested was carried out by LIBS, and the spectral information of the unknown samples was compared with the standard curve to obtain the soil element content

Table 1 Element content in soil determined by LIBS

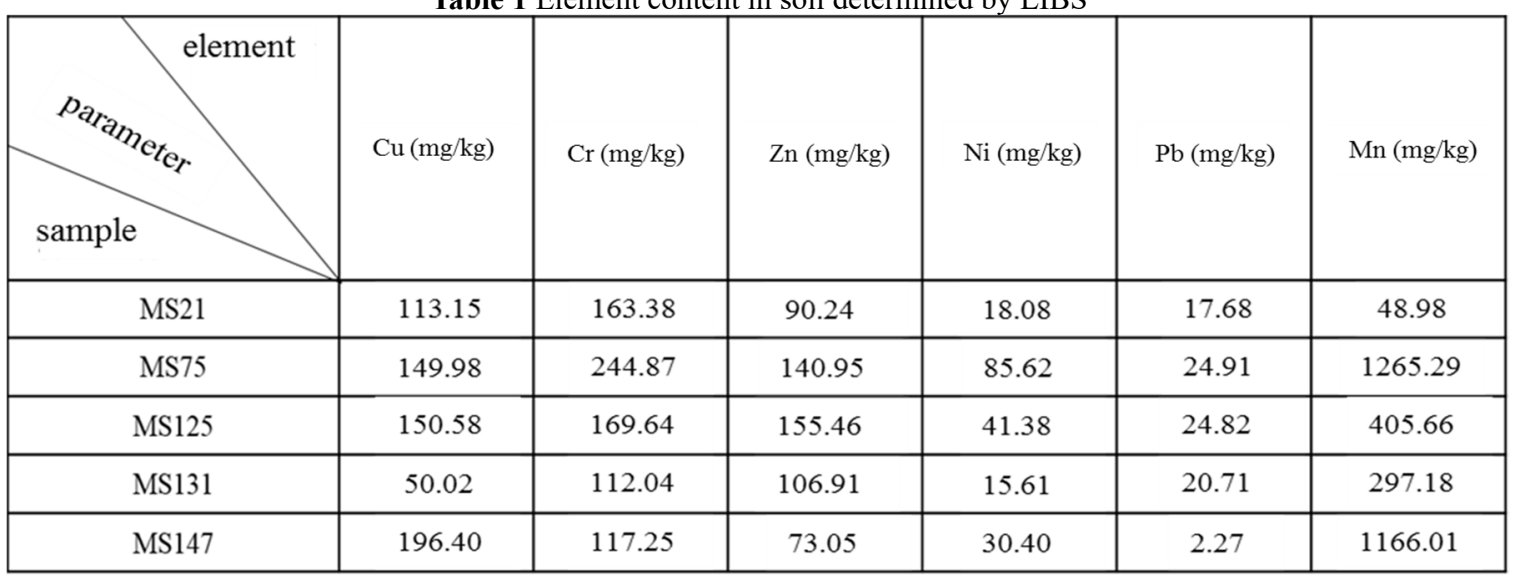

\subsection{Comparative analysis of LIBS and chemical methods}

In order to ensure the reliability of quantitative analysis of LIBS technology, the traditional analytical method inductively coupled plasma atomic emission spectroscopy (ICP-AES) was compared with the LIBS detection results to verify the accuracy of LIBS detection. The traditional measurement method requires the steps of digesting the sample, measuring the machine, and the like. The comparative analysis of the measured element corresponding to the spectral intensity of the different elements. Table 1 shows the results of the detection of several elements in the five groups of soil samples collected from the Masha River Basin.

concentration and LIBS detection results are shown in Table 2.

It can be seen from the table that the concentration error of most elements does not exceed $20 \%$, which basically meets the requirements. But the chemical method used to determine soil elements takes a long time, measuring elements takes about 3-5 hours, and with this system it is possible to complete elemental measurements in seconds and does not require much pretreatment. 
Table 2 Comparative analysis of elements in LIBS technology and chemical methods

\begin{tabular}{|c|c|c|c|c|c|c|c|c|}
\hline \multirow{2}{*}{ Sampling point } & \multicolumn{5}{|c|}{ Cu (mg/kg) } & \multicolumn{4}{c|}{ Cr (mg/kg) } \\
\cline { 2 - 9 } & LIBS & ICP-AES & Absolute error & Relative error & LIBS & ICP-AES & Absolute error & Relative error \\
\hline MS21 & 113.15 & 71.50 & 41.65 & $36.81 \%$ & 163.38 & 127.00 & 36.38 & $22.27 \%$ \\
\hline MS75 & 149.98 & 112.00 & 37.98 & $25.32 \%$ & 244.87 & 246.00 & -1.13 & $0.46 \%$ \\
\hline MS125 & 150.58 & 159.00 & -8.42 & $5.59 \%$ & 169.64 & 152.00 & 17.64 & $10.40 \%$ \\
\hline MS131 & 50.02 & 51.30 & -1.28 & $2.56 \%$ & 112.04 & 106.00 & 6.04 & $5.39 \%$ \\
\hline MS147 & 196.40 & 164.00 & 32.40 & $16.50 \%$ & 117.25 & 90.90 & 26.35 & $22.47 \%$ \\
\hline
\end{tabular}

\begin{tabular}{|c|c|c|c|c|c|c|c|c|}
\hline \multirow{2}{*}{ Sampling point } & \multicolumn{4}{|c|}{$\mathrm{Zn}(\mathrm{mg} / \mathrm{kg})$} & \multicolumn{4}{|c|}{$\mathrm{Ni}(\mathrm{mg} / \mathrm{kg})$} \\
\hline & LIBS & ICP-AES & Absolute error & Relative error & LIBS & ICP-AES & Absolute error & Relative error \\
\hline MS21 & 90.24 & 36.10 & 54.14 & $59.99 \%$ & 18.08 & 18.50 & -0.42 & $2.30 \%$ \\
\hline MS75 & 140.95 & 116.00 & 24.95 & $17.70 \%$ & 85.62 & 88.90 & -3.28 & $3.83 \%$ \\
\hline MS125 & 155.46 & 99.90 & 55.46 & $35.74 \%$ & 41.38 & 37.80 & 3.58 & $8.66 \%$ \\
\hline MS131 & 106.91 & 85.50 & 21.41 & $20.03 \%$ & 15.61 & 15.50 & 0.11 & $0.68 \%$ \\
\hline MS147 & 75.05 & 127.00 & -51.95 & $69.21 \%$ & 30.40 & 30.40 & -9.40 & $30.92 \%$ \\
\hline \multirow{2}{*}{ Sampling point } & \multicolumn{4}{|c|}{$\mathrm{Pb}(\mathrm{mg} / \mathrm{kg})$} & \multicolumn{4}{|c|}{$\mathrm{Mn}(\mathrm{mg} / \mathrm{kg})$} \\
\hline & LIBS & ICP-AES & Absolute error & Relative error & LIBS & ICP-AES & Absolute error & Relative error \\
\hline MS21 & 17.68 & 16.70 & 0.98 & $5.57 \%$ & 48.98 & 52.60 & -3.62 & $7.38 \%$ \\
\hline MS75 & 24.91 & 18.00 & 0.91 & $27.75 \%$ & 1265.29 & 1385.00 & -119.71 & $9.46 \%$ \\
\hline MS125 & 24.82 & 23.80 & 1.02 & $4.12 \%$ & 405.66 & 432.00 & -26.34 & $6.49 \%$ \\
\hline MS131 & 20.71 & 21.50 & -0.79 & $3.81 \%$ & 297.18 & 324.00 & -26.82 & $9.03 \%$ \\
\hline MS147 & 2.27 & 2.77 & -0.50 & $22.07 \%$ & 1166.01 & 1450.00 & -283.99 & $24.36 \%$ \\
\hline
\end{tabular}

\section{Optimization of LIBS analysis method}

Although LIBS technology has many advantages, there are still some problems in quantitative analysis and spectral line extraction. The research work of LIBS quantitative analysis method and spectral enhancement method in recent years is discussed.

\subsection{Optimization of quantitative analysis methods}

LIBS technology can improve its own detection accuracy and sensitivity by combining data analysis methods. the research of LIBS combined with different data analysis methods is shown in Table 3. 
Table 3 A summary of several studies dealing with LIBS quantitative analysis of soil

\begin{tabular}{cccc}
\hline Analytes & Operational parameters of laser & Remarks & Reference \\
\hline $\mathrm{Pb}$ & $532 \mathrm{~nm}, 10 \mathrm{~Hz}, 2 \mathrm{~mJ}, 10 \mathrm{~ns}$ & Internal standard method & {$[16]$} \\
$\mathrm{Pb}$ & $1064 \mathrm{~nm}, 2 \mathrm{~Hz}, 60 \mathrm{~mJ}, 8 \mathrm{~ns}$ & Internal standard method & {$[17]$} \\
$\mathrm{Pb}, \mathrm{Cr}$ & $1064 \mathrm{~nm}, 10 \mathrm{~Hz}, 200 \mathrm{~mJ}, 10 \mathrm{~ns}$ & Internal standard method & {$[18]$} \\
$\mathrm{Cr}$ & $355 \mathrm{~nm}, 3 \mathrm{~Hz}, 3 \mathrm{~mJ}, 7 \mathrm{~ns}$ & PLSR, ANN & {$[19]$} \\
$\mathrm{Al}, \mathrm{Ca}, \mathrm{Cu}, \mathrm{Fe}, \mathrm{Cr}$ & $266 \mathrm{~nm}, 20 \mathrm{~Hz}, 4.2 \mathrm{~mJ}, 5 \mathrm{~ns}$ & ANN & {$[20]$} \\
$\mathrm{Mn}, \mathrm{Cr}, \mathrm{Cu}, \mathrm{Pb}, \mathrm{Ba}$ & $532 \mathrm{~nm}, 3 \mathrm{~Hz}, 40 \mathrm{~mJ}, 8 \mathrm{~ns}$ & GA, PLS & {$[21]$} \\
$\mathrm{Pb}$ & $1064 \mathrm{~nm}, 2 \mathrm{~Hz}, 110 \mathrm{~mJ}, 8 \mathrm{~ns}$ & 9 spectral smoothing, MSC, PLS & {$[22]$} \\
$\mathrm{Cu}$ & $1064 \mathrm{~nm}, 1 \mathrm{~Hz}, 25 \mathrm{~mJ}, 4 \mathrm{~ns}$ & ANN & {$[23]$} \\
$\mathrm{Cu}$ & $1064 \mathrm{~nm}, 1 \mathrm{~Hz}, 100 \mathrm{~mJ}$ & BP-ANN & {$[24]$} \\
$\mathrm{Cr}$ & $1064 \mathrm{~nm}, 1 \mathrm{~Hz}, 100 \mathrm{~mJ}$ & PCA, PLSR & {$[26]$} \\
$\mathrm{Cd}, \mathrm{Pb}$ & $532 \mathrm{~nm}, 1 \mathrm{~Hz}, 100 \mathrm{~mJ}, 8 \mathrm{~ns}$ & MLR, PLSR, LS-SVN, BP-ANN & {$[27]$} \\
\hline
\end{tabular}

The internal standard method can reduce the influence of the matrix in the sample and the experimental conditions on the detection results and is often used as a quantitative analysis method of correcting matrix effects. Lu et al. [16] analyzed lead in soil by using the internal standard method. The results showed that the linear correlation coefficient between the atomic linear intensity ratio $\mathrm{IPb} / \mathrm{IMn}$ and the sample $\mathrm{Pb}$ concentration was as high as 0.9949 , showing a clear linear relationship. Chen et al. [17] used internal standard method to detect $\mathrm{Pb}$ in soil. As shown in Figure 5, the $\mathrm{Pb}$ calibration curve established by the internal standard

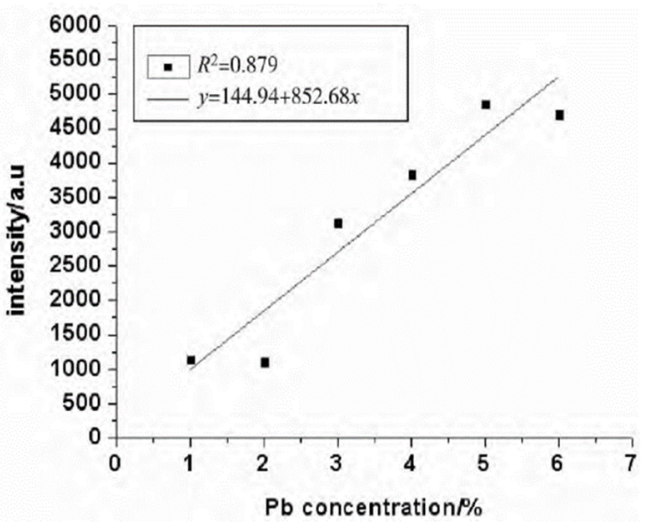

Fig.5 Calibration curve of $\mathrm{Pb}$ concentration and peak intensity

Considering that there are interferences in the detection of the characteristic spectral lines of the other elements in the sample, multi-element line information can be used to reduce the error of quantitative analysis. Sirven et al. [19] used the LIBS technique to detect chromium in soil and compared the traditional quantitative analysis methods, partial least squares regression (PLSR) and artificial neural network (ANN). Neural networks were shown to correctly model nonlinear effects due to self-absorption in the plasma and improve detection accuracy. Haddad et al. [20] used this method to detect $\mathrm{Al}, \mathrm{Cu}, \mathrm{Fe}, \mathrm{Ca}$ in soil and obtained similar conclusions. Based on the genetic algorithm (GA) and partial least squares (PLS), Zou et al. [21] established a heavy metal quantitative analysis model and used LIBS to detect chromium, copper and lead. The method had a higher degree of fitting than the calibration curve established by the traditional method. Bai [18] analyzed the contents of chromium and lead in soil by LIBS, and compared the accuracy of LIBS analysis results with iron atoms and the background of the analytical line as internal standard and no internal standard. The results showed that the linear correlation coefficient of the calibration curve was as high as 0.9993 when the Fe spectral line was selected as the internal standard line, which can eliminate the influence of experimental conditions on the analysis results.

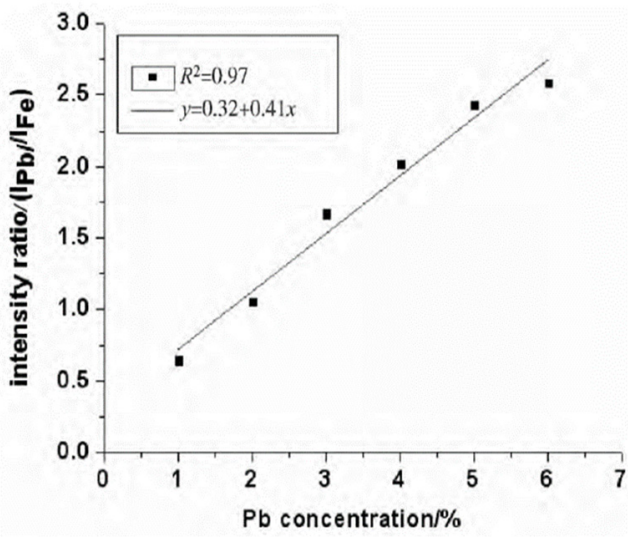

Fig.6 Calibration curve of $\mathrm{Pb}$ concentration of Fe element as internal standard

results showed that the GA-PLS model can Improve the accuracy of detection and significantly improve the performance of the traditional PLS model.

Chen et al. [22] used a variety of spectral pretreatment methods to analyze the content of $\mathrm{Pb}$ in the national standard soil and compared the effect of spectral pretreatment methods of the quantitative prediction ability of the PLS model. The results showed that the multi-point smoothing pretreatment and multi-dimensional scattering Corrected pre-processed models had very good quality. Ferreira et al. [23] used artificial neural networks (ANN) to analyze the copper in the soil. The results showed that when the concentration of $\mathrm{Cu}$ in soil samples was higher than $2.3 \mathrm{mg} / \mathrm{dm} 3$, the detection accuracy was high. Meng et al. [24] also used ANN to analyze $\mathrm{Cu}$ in various types of soils with an error of less than $16 \%$. The results showed that under various 
soil matrices, BP neural network detection error was less than $16 \%$ and can detect cu elements in different soils.

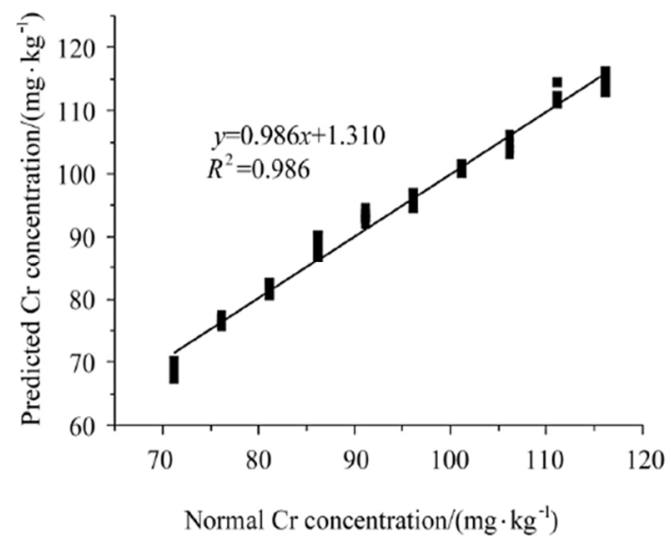

Fig.7 Calibration curve with PLSR of test set

On the other hand, the accuracy of LIBS in classification can be improved by introducing chemometric methods (PCA, PLS-DA, etc.) [25]. GU et al [26] used principal component analysis to classify soil samples and combined with partial least-squares regression method to detect $\mathrm{Cr}$ content in different soils. The results of the study are shown in Figure 7 . The relative error of $\mathrm{Cr}$ content of similar soil was less than $7.5 \%$, indicating that principal component analysis can improve the detection accuracy of heavy metals. XIANG et al. [27] used chemometrics methods to detect and analyze $\mathrm{Pb}$ and $\mathrm{Cd}$ elements in soil and compared the prediction accuracy of MLR, PLSR, and BP-ANN methods. The results showed that the establishment of

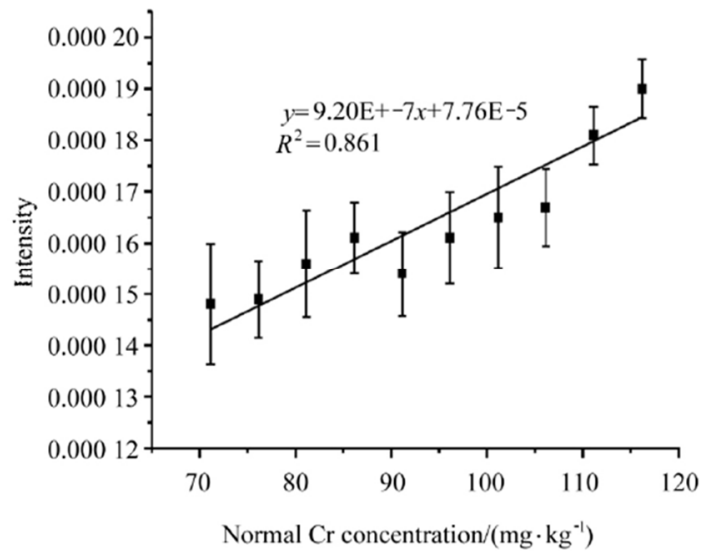

Fig.8 Calibration curve with conventional quantitative method

LS-SVM model and BP-ANN model can improve the detection accuracy to some extent.

\subsection{Method to enhance spectral signal}

The LIBS spectral signal is unstable due to fluctuations in experimental system parameters, changes in experimental environmental conditions, and the like. Therefore, How to enhance LIBS signal from soil has been a hot topic among researchers. The research of the LIBS combined with different spectral enhancement methods is listed in Table 4.

Table 4 A summary of several studies dealing with LIBS combined with data processing Methods for soil detection

\begin{tabular}{|c|c|c|c|}
\hline Analytes & Research result(Intensity, SNR, LOD) & Remarks & Reference \\
\hline $\mathrm{Cr}$ & $1.4 \mu \mathrm{s}, \quad 140 \mathrm{~mJ}$ & Delay time, laser Energy & [31] \\
\hline $\mathrm{Al}$ & $1.5 \mu \mathrm{s}, \quad 120 \mathrm{~mJ}$ & Delay time, laser Energy & [32] \\
\hline $\mathrm{Ca}, \mathrm{Ba}, \mathrm{Li}, \mathrm{Si}, \mathrm{Na}, \mathrm{Cu}$ & LIBS detection accuracy is improved & DP-LIBS, SP-LIBS & [34] \\
\hline $\mathrm{Al}, \mathrm{Mg}, \mathrm{Fe}, \mathrm{Mn}, \mathrm{Co}, \mathrm{Si}, \mathrm{Ti}$ & Intensity: 5 times ( & DP-LIBS & {$[35]$} \\
\hline $\mathrm{Cr}$ & LOD: $15.68 \mathrm{ppm}$ & DP-LIBS & [36] \\
\hline $\mathrm{Mn}, \mathrm{Cr}, \mathrm{Cu}, \mathrm{Pb}$ & $\begin{array}{l}\text { RSD: } 2 \text { to } 3 \text { times } \\
\text { SNR: } 2 \text { to } 3 \text { times }\end{array}$ & DP-LIBS & [37] \\
\hline $\mathrm{Pb}, \mathrm{Mg}, \mathrm{Sn}$ & Mn: 2.75 times & LA-FPDPS & {$[38]$} \\
\hline $\mathrm{Fe}, \mathrm{Al}, \mathrm{Ti}$ & Intensity: 3 to 5 times ( & hemispherical spatial & [39] \\
\hline $\mathrm{Cd}, \mathrm{Cu}, \mathrm{Cr}$ & Intensity: 2 to 3 times ( & confinement & \\
\hline $\mathrm{Mn}, \mathrm{K}, \mathrm{Fe}, \mathrm{Ti}$ & $\begin{array}{c}\text { Intensity: } 90.77 \%, \quad 101.71 \%, 104.27 \%, 60.77 \% \text { ( ) } \\
\text { SNR: } 54.29 \%, 55.30 \%, 59.37 \%, 38.80 \%\end{array}$ & small carbon chamber & [40] \\
\hline As, $\mathrm{Fe}$ & AS: 3 times, $\mathrm{Fe}: 10$ times $(\neg)$ & small chamber in brass & {$[41]$} \\
\hline $\mathrm{Cu}, \mathrm{Ag}$ & LOD: $30 \mathrm{ppm}$ and $23.3 \mathrm{ppm}$ & Microwave-assisted LIBS device & {$[42]$} \\
\hline
\end{tabular}

\subsubsection{Work parameter optimization}

When laser-induced breakdown spectroscopy is used to analyze elemental elements, the laser energy and delay time in the operating parameters will directly affect the spectral intensity, SNR, and background intensity of the laser plasma collected by the spectrometer. In the detection of different matrix elements, the delay time and laser energy optimization are indispensable [28]. In foreign countries, Viskup [29] studied the relationship between LIBS signal and delay time at different pulse times (from 20ns to $500 \mu \mathrm{s}$ ). Wang [30] studied the characteristics of MnI357.788nm and WII364.141nm lines with delay time. The result was shown in Figure 9, the spectral signal became weaker exponentially as the delay time increases. 


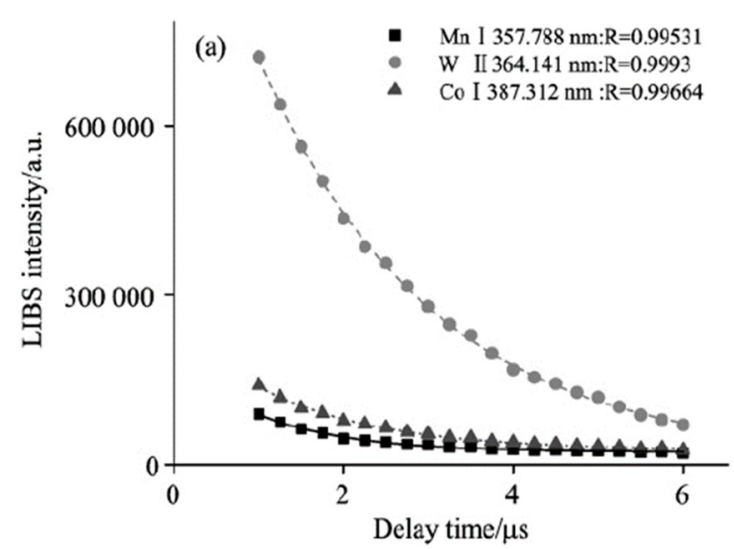

Fig.9 LIBS intensity versus delay time for $\mathrm{MnI} 357.788 \mathrm{~nm}$, WII364.141nm and CoI387.312nm

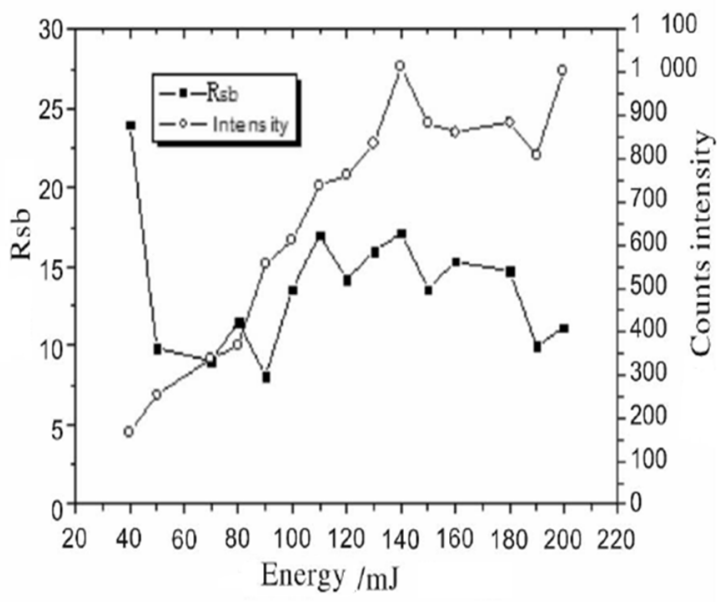

Fig.10 Relation curve of signal-to-background ratio, Strength with different laser energy of chromium

\subsubsection{Experimental device optimization}

In order to enhance the plasma signal, improve the signal-to-noise ratio, and reduce the detection limit [33], researchers often use a variety of different experimental devices such as dual-pulse lasers, space confinement devices, microwave-assisted LIBS devices to enhance the spectrum. Gottfried et al. [34] used the double-pulse LIBS technique to perform non-pretreatment on surface soil and U.S. standard soil in Maryland, California, and other regions. The detection accuracy of soil elements was higher than that of single pulse detection. Nicolodelli et al. [35] used the double-pulse LIBS technique to detect different types of soil. The results showed that the intensity of the different lines was five times stronger than that of the single line. Guo et al. [36] used double-pulse LIBS technique to analyze heavy metal $\mathrm{Cr}$ in soil, and the detection limit of $\mathrm{Cr}$ element under double pulse was successfully reduced to $15.68 \mathrm{mg} / \mathrm{kg}$. Li et al [37] used LA-SIBS technology to analyze the soil, and compared with the single-pulse SP-LIBS technique, LA-SIBS generated a strong plasma off signal, which greatly enhanced the spectral line intensity of each element. The relative standard error was reduced by 2 to 3 times, the SNR increased by 2 to 3 times. Du et al. [38]
On the basic of this, Li et al. [31] comprehensively considered the influence of delay time and laser energy on the spectral signal and obtained the relationship curve of signal-background ratio, intensity and laser energy, delay time. As shown in Figure 10 and Figure 11, the optimum energy was $140 \mathrm{~mJ}$, and the optimal delay time was $1.4 \mu \mathrm{s}$. Zhou et al. [32] used the same method to obtain the optimal operating parameters of the system, in which the laser energy was $120 \mathrm{~mJ}$ and the optimal sampling delay time was $1.5 \mu \mathrm{s}$.

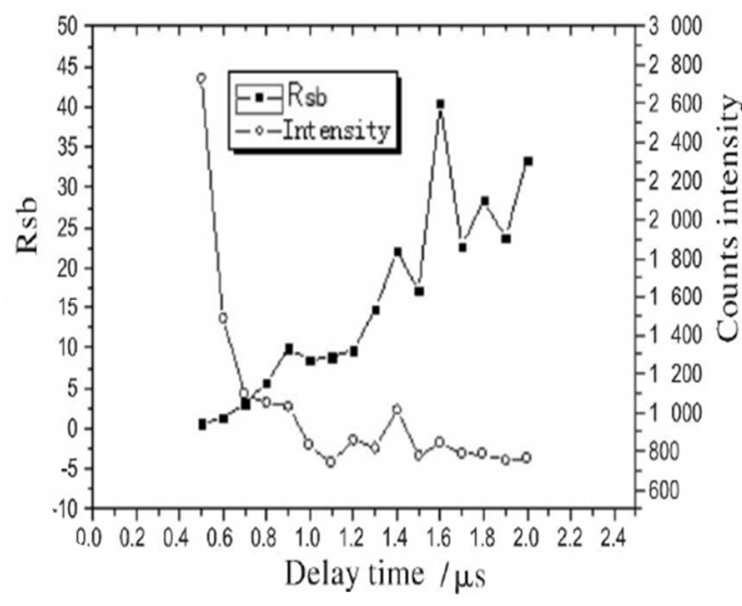

Fig.11 Relation curve of signal-to-background ratio, strength with different delay time of chromium

used orthogonal double-pulse LIBS to detect and analyze $\mathrm{Mn}, \mathrm{Cr}$ and other elements in soils in different regions. Under double pulse conditions, the Mn line intensity was increased by 2.75 times.

Meng et al. [39] used spatial confinement hemispheres to detect heavy metal elements in the soil and effectively increased the intensity of the spectral lines. The line intensity of $\mathrm{Fe}, \mathrm{Al}$, and $\mathrm{Ti}$ increased by 3 to 5 times, while the intensity of lines of $\mathrm{Cd}, \mathrm{Cr}$, and $\mathrm{Cu}$ increased by 2 to 3 times. Chen et al. [40] used LIBS technology to study the changes in the radiation intensity of high-energy laser plasmas in the presence of carbon and non-carbon cavities and to detect the signal intensities of $\mathrm{Mn}, \mathrm{K}$, and Ti. The results showed that the carbon cavities can improve the spectral intensity and SNR of the plasmas \& Popov et al. [41] used a cavity to spatially constrain the laser-induced plasma, effectively improved the LIBS signal intensity. The intensity of the characteristic lines of As and $\mathrm{Fe}$ are enhanced by 3 and 10 times respectively. Liu et al. [42] used microwave-assisted LIBS devices to detect $\mathrm{Cu}$ and $\mathrm{Ag}$ elements in soil. In this case, $\mathrm{Cu}$ and $\mathrm{Ag}$ elements could be detected. The detection limits were $30 \mathrm{ppm}$ and 23.3 ppm. 


\section{Problems with LIBS technology}

Compared with other traditional elemental analysis methods, LIBS technology is widely used in environmental monitoring, industrial production and other fields due to its features of non-destructive testing, real-time, multi-element simultaneous measurement, and detection of samples without being constrained by sample morphology [43,44]. However, unlike the maturity of ICP-AES detection methods, LIBS is a new laser cauterization spectroscopy technique. There is a need for improvement in the reliability, accuracy, and accuracy of quantitative analysis [45]. The main causes of these problems include:

(1) The content of elements in the soil is low, and the intensity of the elemental spectral lines in the LIBS emission spectrum is weak and cannot be easily detected. When the characteristic spectrum of excitation radiation is generated, there is a relatively strong continuous background. In addition, the spectral lines in the LIBS spectrum are affected by the combined effects of various broadening mechanisms, resulting in poor signal back of the element lines. The use of conventional quantitative analysis methods to detect elements content in soil can cause large measurement errors.

(2) Due to fluctuations in the experimental system parameters, changes in the experimental environment conditions, and inhomogeneities in the components of the sample to be measured, the LIBS spectral signal was unstable. By taking the average value of multi-pulsed LIBS spectral data, the problem of unstable spectral data can be solved to some extent. However, how to improve the stability of the spectral signal is still a problem of quantitative detection.

(3) There is a certain difference between the soil matrix components in different regions, and the characteristic spectrum of the plasma is affected by the matrix effect, resulting in a large difference in LIBS spectra between different soils. Therefore, it is necessary to analyze the matrix effects of different soils and improve the quantitative detection accuracy of soil elements by reducing matrix effects.

(4) For actual soil samples, each soil has a different matrix effect, and the relationship between the intensity and concentration of spectral lines is very complicated. The physical factors such as self-absorption effect, matrix effect, and mutual interference between elements affect it, but the degree of influence is not yet clear.

Therefore, how to improve this technology has become the focus of future LIBS research. In the aspect of enhancing the spectral signal, setting the optimum delay time and laser energy of the detection system can effectively enhance the spectrum signal and reduce the background value. In quantitative analysis, the effects of matrix effects in different soils need to be considered. The PCA first classifies the different soil matrices and then selects appropriate calibration curves or regression models for elements (multiple linear regression, partial least-squares regression, artificial neural network). The effect of matrix effect on the analysis of soil heavy metal content can be effectively corrected and the accuracy of the analysis of the content of the test element can be improved.

\section{Development trends and prospects}

With the improvement of laser technology, the perfection of digital processing technology and the realization of various high-precision algorithms, LIBS have a broad development space in the future $[46,47]$. In the future, the LIBS technology will focus on the development of the core components, the mechanism, and quantitative analysis methods.

In summary, with the advantages of non-destructive testing, real-time, and multi-element simultaneous measurement, LIBS has achieved remarkable results in the detection of soil element analysis in the basin. With the continuous optimization and development of laser technology, people will have a better understanding of LIBS and the solution of technical problems will help LIBS technology gain better application prospects in the field of soil element analysis.

\section{Acknowledgement}

This work was financially supported by the Water Resource Science and Technology Innovation Program of Guangdong Province (No. 201708), the Ministry of Water Resources “948” Program of China (No. 201311).

\section{Reference:}

1. Deng Q J, Wu F C, Xie F. Effect of industrial pollution on concentration of heavy metals in farmland soils[J]. Guizhou Agricultural Sciences, 2009, 37(9):240-244.

2. Yu-Shuang L I. Advances in Soil Remediation Technologies of Urban Industrial Contaminated Sites[J]. Journal of Anhui Agricultural Sciences, 2012, 40(10):6119-6122.

3. Xu Y N, Zhang J H, Ke H L, et al. Human health risk under the condition of farmland soil heavy metals pollution in a gold mining area[J]. Geological Bulletin of China, 2014, 33(8):1239-1252.

4. Chu Y C, Xiao G E, Wei S Y, et al. Growth and Heavy Metal Accumulation of Brassica chinensis Applied with Sewage Sludge Compost[J]. Journal of Agro-Environment Science, 2013, 32(10):1965-1970.

5. LIU Chun-yang, ZHANG Yu-feng, TENG Jie. Advances on Pollution Soils by Heavy Metals[J]. Pollution Control Technology, 2006.

6. $\mathrm{Xu} H \mathrm{H}$, Sun $\mathrm{T}$, Jiang $\mathrm{X}$ J. Simultaneous determination of zinc, chromium, lead, cadmium, copper and arsenic in waste water by inductively coupled plasma atomic emission spectrometry[J]. Metallurgical Analysis, 2008, 28(11):43-45.

7. Xiao-Yan X U, Sun Y M, Wen-Zhuo S U, et al. Continuous Determination of Lead, Chromium and Cadmium in Fruit and Vegetable by Microwave Digestion-Graphite Furnace Atomic Absorption 
Spectrometry[J]. Food Science, 2009, 30(10):206-208.

8. Xi-Ming M O, Peng Z Y, Shu-Nuan X U, et al. Determination of $\mathrm{Cr}(\mathrm{VI})$ in drinking water by inductively coupled plasma-mass spectrometry[J]. Chinese Journal of Health Laboratory Technology, 2009.

9. Dell'Aglio $M$, Gaudiuso $R$, Senesi $G \mathrm{~S}$, et al. Monitoring of $\mathrm{Cr}, \mathrm{Cu}, \mathrm{Pb}, \mathrm{V}$ and $\mathrm{Zn}$ in Polluted Soils by Laser Induced Breakdown Spectroscopy (LIBS)[J]. Journal of Environmental Monitoring, 2011, 13(5):1422-1426.

10. Capitelli F, Colao F, Provenzano M R, et al. Determination of heavy metals in soils by Laser Induced Breakdown Spectroscopy[J]. Geofisica Internacional, 2002, 106(1):45-62.

11. Xue Fengna. Spatial distribution characteristics of phosphorus and potassium in grassland small watershed based on LIBS technology [D]. Inner Mongolia Normal University, 2017.

12. Wang Qing, Tan Juan, Wu Jian, et al. Application Progress of Laser Induced Breakdown Spectroscopy in the Field of Environment [J]. Environmental Monitoring in China, 2015, 31(3).

13. Arca G, Ciucci A, Palleschi V, et al. Trace Element Analysis in Water by the Laser-Induced Breakdown Spectroscopy Technique[J]. Applied Spectroscopy, 1997, 51(8):1102-1105.

14. Russell S. Harmon, Frank C. De Lucia, Chase A. Munson, et al. Laser-induced breakdown spectroscopy (LIBS): an emerging field-portable sensor technology for real-time chemical analysis for military, security and environmental applications[J]. Proc Spie, 2005, 5(1):59940K-59940K-7.

15. Hahn D W, Omenetto N. Laser-induced breakdown spectroscopy (LIBS), part I: review of basic diagnostics and plasma-particle interactions: still-challenging issues within the analytical plasma community[J]. Applied Spectroscopy,2010, 64(12):335-366.

16. $\mathrm{Lu} \mathrm{Y,} \mathrm{Wu} \mathrm{J} \mathrm{L,} \mathrm{Li} \mathrm{Y,} \mathrm{et} \mathrm{al.} \mathrm{[Experimental}$ investigation of $\mathrm{Pb}$ in soil slurries by laser induced breakdown spectroscopy]. [J]. Spectroscopy \& Spectral Analysis, 2009, 29(11):3121-3125.

17. Tianbing, Huang L, Yao M, et al. Quantitative Analysis of $\mathrm{Pb}$ in Soil Using LIBS and Internal Standard MethodChen[J]. Applied Laser, 2013, 33(6):623-627.

18. Bai Jinning. Study of Laser-Induced Breakdown Spectroscopy used for soil environmental quality monitoring [D]. Hebei University, 2013.

19. Sirven J B, Bousquet B , Canioni L, et al . Laser-induced breakdown spectroscopy of composite samples : comparison of advanced chemometrics methods.[J]. Analytical Chemistry, 2006, 78(5): 1462-1469.

20. Haddad J E, Villot-Kadri M, Ismaël A, et al. Artificial neural network for on-site quantitative analysis of soils using laser induced breakdown spectroscopy[J]. Spectrochimica Acta Part B Atomic Spectroscopy, 2013, s 79-80(3): 51-57.

21. Zou X H, Hao Z Q, Rong-Xing $Y$ I, et al. Quantitative Analysis of Soil by Laser-induced Breakdown Spectroscopy Using Genetic Algorithm-Partial Least Squares[J]. Chinese Journal of Analytical Chemistry, 2015, 43(2):181-186.

22. Chen T B, Yao M Y, Zhou H M, et al. Determination of $\mathrm{Pb}$ concentration in soil sample by laser-induced breakdown spectroscopy with PLS[J]. Laser \& Infrared, 2014.

23. Ferreira E C, Milori D M B P, Ferreira E J, et al. Artificial neural network for $\mathrm{Cu}$ quantitative determination in soil using a portable Laser Induced Breakdown Spectroscopy system[J]. Spectrochimica Acta Part B Atomic Spectroscopy, 2008, 63(10):1216-1220.

24. Meng D S, Zhao N J, Ming-Jun M A, et al. Quantitative detection of $\mathrm{Cu}$ in different types of soils using laser induced breakdown spectroscopy combined with artificial neural network[J]. Journal of Optoelectronics · laser, 2015.

25. Du Q C, Zhang Z Z, Ju Y. Research advances of the application of laser-induced breakdown spectroscopy on metal element detection [J]. Shandong Science, 2018, 31(2):55-63.

26. Yan-Hong G U, Zhao N J, Ming-Jun M A, et al. Quantitative analysis of $\mathrm{Cr}$ in soils using LIBS with principal components regression[J]. Journal of Optoelectronics ' laser, 2016, 27(7):748-753.

27. Xiang L R, Ma Z H, Zhao X Y, et al. Comparative Analysis of Chemometrics Method on Heavy Metal Detection in Soil with Laser-Induced Breakdown Spectroscopy[J]. Spectroscopy and Spectral Analysis, 2017, 37(12):3871-3876.

28. Huang J S. Determination of Some Heavy Metals in Soil by Laser Induced Breakdown Spectroscopy[D]. Zhejiang Normal University, 2009.

29. Viskup R, Praher B, Linsmeyer T, et al. Influence of pulse-to-pulse delay for $532 \mathrm{~nm}$ double-pulse laser-induced breakdown spectroscopy of technical polymers[J]. Spectrochimica Acta Part B Atomic Spectroscopy, 2010, 65(11):935-942.

30. Wang Y E. [Influence of delay time on laser-induced breakdown spectroscopy of limestone $][\mathrm{J}]$. Guang pu xue yu guang pu fen $\mathrm{xi}=$ Guang pu, 2013, 33(5):1180.

31. Li Wenbing, Jiangxi Agricultural University. Parameter Optimization of LIBS in Detecting Chromium in Smelter Soil[J]. Acta Agriculturae Universitatis Jiangxiensis, 2013.

32. Zhou W, Liu Y, Huang J. Effects of Parameters on Spectrum Characteristics of Laser Induced Soil Plasma[J]. Journal of Atmospheric \& Environmental Optics, 2016.

33. Zhao N, Yanhong G U, Meng D, et al. Technique 
Progress and Development Trend of Laser-Induced Breakdown Spectroscopy[J]. Journal of Atmospheric \& Environmental Optics, 2016.

34. Gottfried J L. Multivariate Analysis of LIBS Spectra for Geomaterial Identification, Discrimination, and Classification[J]. 2008.

35. Nicolodelli G, Senesi G S, Romano R A, et al. Signal enhancement in collinear double-pulse laser-induced breakdown spectroscopy applied to different soils $\hat{z}[\mathrm{~J}]$. Spectrochimica Acta Part B Atomic Spectroscopy, 2015, 111:23-29.

36. Guo R, Song H. Analysis of Heavy Metals Chromium in Soil Using Double Pulse Laser-Induced Breakdown Spectroscopy[J]. Journal of Taiyuan University of Technology, 2014.

37. Li K X, Zhou W D, Shen Q M, et al. Laser ablation assisted spark induced breakdown spectroscopy on soil samples[J]. Journal of Analytical Atomic Spectrometry, 2010, 25(9):1475-1481.

38. Du C. Analyses of heavy metals by soil using dual-pulsed laser induced breakdown spectroscopy[J]. Acta Physica Sinica, 2013, 62(4):221-229.

39. Meng D S, Zhao N J, Ma M J, et al. Heavy Metal Detection in Soils by Laser Induced Breakdown Spectroscopy Using Hemispherical Spatial Confinement[J]. Plasma Science and Technology, 2015, 17(8): 632-637.

40. CHEN Jin-zhong, MA Rui-ling, CHEN Zhen-yu, et al. Enhancement effect of carbon chamber confinement on laser plasma radiation[J]. Optics \& Precision Engineering, 2013, 21(8):1942-1948.

41. Popov A M, Colao F, Fantoni R. Enhancement of LIBS signal by spatially confining the laser-induced plasma[J]. Journal of Analytical Atomic Spectrometry, 2009, 24(5):602-604.

42. Liu Y, Bousquet B, Baudelet M, et al. Improvement of the sensitivity for the measurement of copper concentrations in soil by microwave-assisted laser-induced breakdown spectroscopy[J]. Spectrochimica Acta Part B Atomic Spectroscopy, 2012, 73(73):89-92.

43. Koskelo A C, Eppler A S, Cremers D A, et al. Matrix Effects in the Detection of $\mathrm{Pb}$ and $\mathrm{Ba}$ in Soils Using Laser-Induced Breakdown Spectroscopy[J]. Applied Spectroscopy, 1996, 50(9):1175-1181(7).

44. Lanza N L, Ollila A M, Cousin A, et al. Understanding the signature of rock coatings in laser-induced breakdown spectroscopy data[J]. Icarus, 2015, 249:62-73.

45. Fichet P, Tabarant M, Salle B, et al. Comparisons between LIBS and ICP/OES[J]. Analytical \& Bioanalytical Chemistry, 2006, 385(2):338-44.

46. Chan G C Y, Choi I, Mao X, et al. Isotopic determination of uranium in soil by laser induced breakdown spectroscopy[J] Spectrochimica Acta Part B Atomic Spectroscopy, 2016, 122:31-39.

47. Campbell K R, Wozniak N R, Colgan J P, et al.
Phase discrimination of uranium oxides using laser-induced breakdown spectroscopy[J]. Spectrochimica Acta Part B Atomic Spectroscopy, 2017, 134. 